\title{
Reflexive Dressing
}

\section{Rethinking Retro}

\author{
StELLA NORTH
}

INDEPENDENT SCHOLAR

Where are we when we think?

Hannah Arendt

The moment of dressing: corporeal reflexivity made manifest. Turning our embodied attention, if only a partial and splintered attention, to our meeting with the world of matter, we compose ourselves in textile forms. They, in turn, will materially form us in the world of the visual. The moment of dressing is a moment of grappling with intimacies and interfaces: of the inward subject of perception with its outward object; of the seen with the felt; of the body's surface with the surface that is clothing: of the corporeal being with the world of matter. At the dimensional crossroads of these interfacial intersections, the dresser stands as the answer to questions not asked consciously: How am I material? How does looking feel? Where is the line between me and the world? These questions in turn regenerate Arendt's

ISSN 1837-8692

Cultural Studies Review 2016. ( 2016 Stella North. This is an Open Access article distributed under the terms of the Creative Commons Attribution 4.0 Unported (CC BY 4.0) License

(https://creativecommons.org/licenses/by/4.0/), allowing third parties to copy and redistribute the material in any medium or format and to remix, transform, and build upon the material for any purpose, even commercially, provided the original work is properly cited and states its license. 
evocative phrase, in altered form: 'Where am I when I dress?' (The 'we' of Arendt's question is present in the 'I' of mine, for one of the interfaces negotiated in dressing is precisely that between the first person singular and plural, that is, between the individual and the collective.) ${ }^{1}$

We could further ask: 'When are we when we dress?' Applying particularly to that form of clothing described as 'retro,' this question is also salient for dressing qua dressing, in that the moment of dressing is always itself in a relation to time. It has this in common with thinking, which as Arendt tells us 'always deals with absences and removes itself from what is close at hand'. ${ }^{2}$ When, in thinking, we 'begin to direct our attention onto the activity itself' - that is, when we think about thinking-'past and future are equally present because they are equally absent from our sense'. ${ }^{3}$ In the moment of dressing (or of thinking about dressing), a moment which draws on both past and future, it is rather we who are equally present and absent to time. To think of dress is thus to think of time twice over; once for the place time opens up in thought, and once for the temporalised nature of dress itself. The act of dressing is Janus-faced, looking forward and backward at once. Dressing deals with, is in fact founded on, a self doubled; in it the mental is entwined with the material, internal with external, past with present, known with unknown. The question posed by my enquiry into dressing is implicitly one the act itself must ask: 'Who am I when I dress?'

In pursuing these enquiries, I begin with one more basic: 'What are we doing when we dress?' It has to do, we assume, with the application of stylistic articles; not just cloth garments, but also complementary forms of matter-accessories, worn objects of all sorts-that form part of the effects of dress; what we might refer to collectively, emphasising both their materiality and their position as acted-upon, as clothing-objects: objects in the sense of 'things', objects in the sense of that which receives a transitive verb. Dressing is in this view fundamentally compositional, a process of determining, in Karen Tranberg Hansen's phrase, 'how, when and where the body is put together with clothing'; ${ }^{4}$ or, in my terms, with clothing-objects. The phrase 'put together' works here in two senses: the body combined with its dress, and constructed by it. It also appears in fashion discourse as a term of approbation; someone whose dressed appearance has a high degree of polish and coherence is described as looking 'put together'. ${ }^{5}$ So, in dressing, we are putting an outfit 
together, putting the body together with its clothing-objects, putting together a dressed image that aims at a complete sartorial surface. The greater the degree to which said image can be described as 'put together', the more successful the illusion of completion.

Slowing down the workings of this understanding of dressing, we have something like the following: 'In a given context, and with some reference to what is viable in that context, and to those I anticipate entering in the immediate future, I select clothing-objects and place them on my body, with varying degrees of adjustment depending on the success of that first placement.' There are, of course, complications even in this very basic, ostensibly commonsensical picture; any instance of dressing will be framed at the least by issues of access and constraint, of 'fit' in both its sartorial and its moral sense, as well as their relation. But there is a more fundamental complication yet. I said, and we imagine, that I place clothes on my body, as though the transitivity of dressing were clear, linear. 'I place'-'on my body', with clothing the connective tissue between. Such a sentence, such a conception, sweeps over the fact that this 'I' who places is none other than the corporeal entity upon whom the clothing-objects are placed: the dresser is internal to the dressing, to contort the Yeatsian phrase. Irrespective of how alienated the dresser's agency might be by the constraints of her context, it is her corporeal reality by which, as well as to which, that agency is applied. Put very simply: it is not a question of some outside agency 'dressing the body', because it is the body that dresses.

And so my earlier choice of preposition wants revision. It is in an important sense not the whole story to say, as I vernacularly so easily might, that I 'put clothing on my body', or even that my agentive body in a reflexive mode 'puts clothing on' itself-'putting' clothing on the body as on a peg. Rather, it is more that my body (a body constituted by thought, inflected through variable levels of will and restraint) takes itself, and places itself, in clothes. 'Places itself in': derives reflexively a sense of place, bounded in the dimensional surface that is clothing. What I am doing when I dress is done bodily; dressing is the body locating itself in the frame it will have relative to the material world. ${ }^{6}$ From this a further question follows: how are the particular clothing-objects that will form this frame selected? And according to what metric? 
One way of thinking about this question can be found in the 1995 film Clueless. ${ }^{7}$ Itself an icon of its decade, the film presents a further icon of the era: the computerised closet of its protagonist, Cher, a construct which serves several functions. Each garment, categorised by type, exists as an image on the device's screen, such that the digital closet serves as both an archive of garments, and as a means of viewing them. Additionally, as demonstrated in the film's first scene, it serves as an externalisation of the decision-making faculty employed in the act of dressing. In our position as viewer, we see garments flash across the screen-withina-screen as Cher flicks through potential combinations, each vetoed by the device as a 'MIS-MATCH', until a successful pairing is attained. The closet-approved outfit Cher eventually wears to school, a yellow plaid kilt-and-cropped-jacket ensemble, has, like many stylistic aspects of the film, become its distinctive and much-imitated metonym. This image is seen, within the film, (1) as a disembodied image on the computer screen, then (2) applied to an image of Cher's body within the field of that intra-diegetic screen, then (3) as a three-dimensional worn reality on the full screen of the film. The progression in Cher's computer-assisted act of getting dressed-a sartorial idea (1) applied imagistically to one's body (2) and then realised materially (3) - is that which takes place in dressing per se. Contrived as the film's vision of automated dressing is, in capturing something of the psychical experience of picking out clothes it provides at least a partial answer to the question of what-in mind, in body, at their interface-we are doing when we dress.

The vision Clueless presents, of dressing as questing, accords with that of Lorelei Vashti, who, in trying on multiple items of clothing, sought 'a feeling rather than a look ... I couldn't explain what I was trying to achieve but when I hit on it I knew'. ${ }^{8}$ This word, feeling, is pervasive in fashion-speak. Used either as a verb of opinion, synonymous with 'liking' or 'enjoying' ('I'm feeling dark denim jackets this spring'), or as a noun of characterisation for a given garment, season or collection ('there has been a distinctly '90s feeling in fashion of late'), it is used more than it is examined. ${ }^{9}$ The word is circular; it refers a nebulous sartorial atmosphere perceived in some manifestation of style back to the operation of that perception. Circular, too, is the interface of experience and matter in the experience of dressing, and it is perhaps this to which the fogginess of 'feeling' points. But the question remains: 
what, exactly, is being felt? And by what aspect of the speaker whose selfperpetuating perception is thus asserted?

What demands further explanation, in Vashti's summation and in all its kindred utterances in fashion discourse, is how 'feelings' are translated into 'looks', and vice versa. Again, Cher's computerised closet provides a model. It generates an outfit by testing one variable against another to see what connects; we, in dressing, do the same, with the difference that one variable is our corporeal state (or our mysterious intercorporeal 'feeling'), and the other the potential outfit. Possessed of a perceptual desire, or inkling, or intention, we cycle through garments, or combinations of garments, until we find a resonance. Whether our cycling is in internal rumination, or physical rummaging through collected clothes, we are seeking, like the closet, to match our sartorial impulse with an outfit that realises it. The 'feeling' is like a card formed of past perceptions, played in dressing against the shuffled cards of potential future outfits in hopes of finding that sense of an internally shouted 'Snap!' that marks the moment of sartorial satisfaction. The mysterious image crunching undertaken by the automated closet thus mirrors the equally mysterious (and perhaps equally automatic) corporeal calculations taking place within ourselves when we undertake to dress. Which is to say, perhaps dressing is a kind of thinking, and the manifestation, in matter, of earlier thought-experience, revisited as 'feeling'.

The paying of reflexively refined visual attention in dressing is akin to what Leanne Shapton, in describing her internalisation of other women's style, calls 'cumulative lessons in being myself'.10 Each past experience of dressing is one of these layered lessons in self-perception, even if what is learned is self-refusal. The kind of querying attention that dressing entails-the quarrying of sensations temporal and corporeal, veined around each other and through much inward rockamounts to a cumulative realisation of that perception, the mounting complication of what 'being oneself' might after all entail.

And this visual thought-feeling, by which the act of dressing is driven, is corporeally received and corporeally rendered. It is an impulse in the ankles to be swept over by the hem of a long dress, or a stretching in the hands for pockets into which to be plunged. It is a yearning in the legs for the clipped certainty of gait formidable boots induce, or in the head for the softened composure of hair bunched at its base; it is hips hearkening to the equilibrating weight of a full skirt, or a spine 
speaking for the kind of carriage the weight of such a skirt could derive. It is a suggestion, in the shoulders, that a sweater's boatneck could be a straightening horizon, or, in the neck, that it could be a Plimsoll Line above which to rise; or it is something else entirely. ${ }^{11}$

The dressing sense of 'feeling' is like an inchoate question the body asks, hoping clothing will give an answer. The question may be inaudible, so that it is answered before thought can hear it, or is left hanging. Or the garment 'felt' for may be unavailable, such that the garment eventually settled upon is a stop-gap, or selected precisely for its distance from the unfulfillable instinct (a motion of dressing against desire); perceptible or not, the corporeal question, the flexion of the body into the shape of its asking, inflects the experience of selection. The choice of clothing-object is produced, however unconsciously, by the motion of those inquisitive antennae; as a tendering of experience in matter, a stepping forward of perceptual sensitivity.

In the reach of the body towards the clothing-object, there is a to-and-fro of 'looking' and 'feeling', internalising and externalising. Our embodied attention, going about its day-to-day life, is all the time taking in 'looks' as 'feelings', putting them through internal algorithms of embrace and refusal, memory and dismay, then reexperiencing those feelings when dressing, in order to project them outward as a 'look', to realise one (or more than one) of them in the visible world. Each feeling is of, and in, and for the body, and it is by the body that those which can be retrieved will be reflexively rendered as dressed effect. This is not to say that the 'feeling' is opposed to thought. Rather, it is a mode by which thought can be materialised: dressing is a means of thinking with the body, an act in which the body produces what it will be out of what it has known.

In light of all this, dressing can be described as the corporeally driven arrangement, often the rearrangement, of the subtle residues of worldly experience in order to materially compose an approach to the world, however variable, or internally various, such an approach may be. As, for Arendt, in thinking, 'I am not where I actually am; I am surrounded not by sense objects but by images that are invisible to everybody else', in dressing I am both present and absent, seeing (and seeing bodily) not only the clothing-objects on which I draw but the associative depths they draw on in turn. ${ }^{12}$ Where are we when we dress? At the juncture of object and subject; acted upon by our dressed intention, actor in so far as it is us 
who intends. We are bringing to our worldly surface, a surface not opposed to depth, a surface which is itself constitutive of psychic selfhood, an understanding of ourselves as surface. ${ }^{13}$ When we dress, we are here, and there, subject and object; in a realm of perceptual testing, at the intersection of the visual and the sensual, the active and passive, the absent and the present, and reckoning with ourselves as comprising these interfaces. The clothing-object is that for which we reach, but it reaches us in turn, seeming to cause us to 'feel' it in whatever way we do. We experience our receipt of clothing-as-feeling as beginning in some sense with that object; it is sensed, responded to, as a subject, both verbal and experiential. And this sense of 'feeling' is inextricable from a sense of time; even the simplest fashiondiscursive uses of the term refer to a broader temporal swathe, in addition to the verb's present tense; 'I'm feeling gray ankle boots this winter', or 'the feeling on the catwalk this season was one of louche luxury'. Time is thus central to what is felt.

The 'feeling' of style is a way of being in the present, a way of explaining visually to yourself, via the past (or many pasts) what the present is, and how you are in it. Dressing moves toward the future, even if it gets there via the past; more, it is suspended between the two. In this it again resembles thought, which, as elucidated by Arendt, deals in absences: 'The gap between past and future opens only in reflection, whose subject matter is what is absent, either what has already disappeared or what has not yet appeared.'14 The temporal gap of thinking is the space in which dress is situated, in which we, through dressing, reflexively situate ourselves. 'Only insofar as [we think]' do we, 'in the full actuality of [our] concrete being, live in this gap between past and future, in this present, which is timeless?'15 That is, the contingency of the present moment rests on the contingency of thought; time and thought are mutually underlying. Arendt goes on to say:

[We live] in this in-between, and what [we call] the present is a lifelong fight against the dead weight of the past, driving [us] forward with hope, and the fear of a future ... driving [us] backward toward 'the quiet of the past' with nostalgia for and remembrance of the only reality [we] can be sure of. 16

As it is thought which locates us in the present, and as, the future being unknown, the present must turn towards the past for its surety, thought by its very nature contains within it a reflexive backwards look. Being thus intrinsically nostalgic, 
thought's taking of nostalgia as its object is an act in the reflexive mode-as is the act of dressing. Past-oriented forms of dress are arguably attempting to grapple with this nostalgia lodged in the heart of thought, to think time materially by means of the visually experienced body. In the sartorial present, we are not just in Arendt's 'gap' where past faces future, but straddling the gulf between the two, faced with the risk of being split across it. The moment in which I dress is a moment of my reckoning with what Dar Williams calls 'the kind of change that severs me in two'.17 Dressing is, like thinking, a way of managing the 'gap' of this potential severance from self, of becoming reconciled not only to the loss involved in the progress of time, but to the doubleness that is fundamental to any notion of self-identity.

Double, too, is the hinging between absence and presence that our entry into the temporal space of dressing entails. In Arendt's formulation, I am absent from the world when I, in contemplation, become present to myself, and present in the world of others to the extent that this contemplative self-accompaniment is absent. ${ }^{18}$ Both thinking and dressing are always having to contend with absence, the absence which inheres in their making-present, always managing the very present severance of presence. However, since dressing has an aim-being 'dressed'-that is at least somewhat social, it partakes of this balancing act between absence and presence in a somewhat different way. In dressing, we are composing, in the momentary absence of the outward world, a way of managing our presence in it, and a means, consequently, of balancing our internal presences and absences with the world they reflect.

When are we when we dress? In an endlessly severed instantaneity in which the body reaches its material present towards its absent visual future, fuelled and impeded in equal measure by its always-incomplete assimilation of its equally absent past. We are in, when we dress, Arendt's 'small non-time space in the very heart of time',19 a seam in the material of the visual-sensual world within which we both partake of it and retreat from it. The approach to dress we place under the sign of 'retro' is only the most explicit case of fashion's tensile relation of commemoration and futurity; retro is the screen on which that relation is writ large.

Classically, retro is understood as a stylistic orientation rooted in a wistful desire to return; a sensitivity, perhaps pathological, to history; a 'feeling' for pastness generally or for one specific past period. With dressing conceived 
corporeally, such an understanding positions retro as a somaticised nostalgia, in which the body replays-or yearns to replay, or laments that it cannot replay-the experiential reality of the past. There are certainly facets of the retro phenomenon that work like this, but they seem to me the tip of a more interesting iceberg. In retailing terms, 'retro' clothing is that from the past twenty to thirty years (though the temporal terms vary), and 'vintage' that which is older still. ${ }^{20}$ This, however, is shifting ground; as the turnaround of stylistic return speeds ever up, as the uses made of 'old clothes' proliferate, and their meanings likewise, it becomes harder and harder to tell where the lines should be drawn; some demarcations of retro's span place its starting point as recently as fifteen years ago. ${ }^{21}$ In the clamour of this perpetual 'return' of what has not yet had time to leave, it becomes difficult to sound the depth of our distance from any given past or future point. Where are we when we dress? Seemingly, everywhere at once.

If, as one definition has it, what marks a style as 'retro' is not its age, but its current fashionability, then all past styles can equally wear the name, regardless of their temporal nearness to or distance from the namer; beyond the standard division where 'retro' marks the immediate past, and 'vintage' a past more distant, there is a sense in which the very turning of dressing's 'feeling' towards the past, any past, is retro.22 Retro in this sense is a matter less of a clothing-object's point of origin and more of an attitude taken to the past made cloth. ${ }^{23}$ Since the very word 'retro' abbreviates 'retrograde', the approach to dressing it describes bears a sense of moving to the future backwards, like a planet appearing to trace its own course in reverse. ${ }^{24}$ Conceived as an attitude taken to dressing, retro, while it appears to run against the temporal current, in fact draws its very currency from the appearance of regression, and the (re)visions of the present that appearance makes apparent. Hilary Alexander describes the practice of dressing in past styles as 'a way of wearing history, [of turning] the past into the present, even the future'.25 While her observation is directed only to those manifestations of style that are backwardslooking, dressing qua dressing arguably negotiates the suspension of the present moment between past and future-the moment which, in Arendt's terms, is the location and the basis of thought. Clothes move us forwards in time, as well as backwards; backwards, as a means of holding onto, or exploring, the past-our personal past, or the collective-and forwards, as a means of anticipating, 
recognising, or rehearsing a future self. So in retro dressing, we are not just placing ourselves corporeally in the clothing-objects of the past as a means of placing ourselves there conceptually, as a commonsense understanding of retro as the pursuit of aesthetic time travel might have it, but contending with ourselves as temporalised beings per se; rather than moving through time, we are materialising, thinking bodily about, how time moves through us. ${ }^{26}$

Retro enacts the perceptual entanglement of pasts and futures. When, for example, in 1994 the soon-to-be hit sitcom Friends deploys, as one of the defining first season looks for the character of Phoebe, a diluted televisual version of Yves Saint Laurent's Autumn/Winter 1976-77 collection 'Russian Ballet and Opera', it gives its mid 1990s audience a dressed image of a current style through the lens of a fantastical past (Saint Laurent's reanimation of Russian folk traditions being itself an exercise in appropriative imagination). ${ }^{27}$ This at once particularises the character of Phoebe through an association with the 1970s, and produces a quintessentially 1990s look that is, for its contemporaneous audience, incorporated into the 'hippie' facet of the decade's style. To look, from the vantage point of the present, at those dressed images of Phoebe is thus to see the 1970s as well as the 1990s. Equally, to look at or wear a current revisitation of a similar 1970s look is to visualise and/or corporealise that decade through the lens of its previous 1990s incarnation. ${ }^{28}$

'Style is the way we let the world move through us', says Alexander Nagel. ${ }^{29}$ As the felt intersection of the world of the past and that of the future, dressing is the way we both move through time, and let time move through us: corporeally. Retro is a corporeal attitude we take to the past. At its most basic, a bodily relation to retro is a retro relation to the body; a self-seeing in the past's frame. This may be an attempt to gain perspective; a woman may invest herself in an era in order to, by getting outside her specificity, take a certain aesthetic vantage on herself. Or it may entail a blend of appropriateness and appropriation: a woman may invest in an era as herself, taking up its style because her shape or appearance seem to befit it. Or the motive may be to pursue a kind of corporeal-sartorial learning; a woman may be drawn to grapple with a previous norm in order to-through alienation, exaggeration, dispersal-assimilate it; to inhabit, let's say, a 1940s silhouette, in order to get a grip on nipped waists and (over)determined shoulders. The armature which underlies such relations to retro, and the multitude of other relations for 
which these examples stand, is a conception of time as manifested in the stylistic hallmarks of an era. This is to say that retro, as an approach to dressing, is something felt. It is not merely that the retro dresser has a sensitivity or attraction to a past era, but that they are 'feeling' time in the body, and manifesting that feeling aesthetically-or perhaps more accurately, aesthetically wrestling with it. In the moment of dressing, hinging between past and future, what experience has wrought up to that moment is taken in hand (or potentially held at arm's length), and turned to meet what is yet to come: the past transmuted into a way of responding to the future. Retro, in this terrain, becomes a means of engaging, through the body, with time-as-style; a kind of aesthetic-temporal empathy.

This is to say that some of the 'looks' we take in as 'feelings' are time materialised visually-experientially: how an era looks is retained as how it feels. What we call the 'look' of an era involves both how it looks from without, and how it looked from within. Crucially, however, those in an epoch are not all in it the same way. Anne Hollander has famously observed that the defining visual-stylistic character of a time period is not perceivable from within it; more accurately, that its distinctiveness is not. 'The tight-laced waist, the periwigged head, and the neck collared in a millstone ruff, along with flattened breasts and blue-jeaned legs, have all been comfortable, beautiful and natural in their time', rendered so by 'the alchemy of visual representation'.30 How clothed bodies look in the now appears from inside that time-space as just How Things Are. It is as though a certain normative orbit exists, a gravitational pull of the present tense upon the visual sense, by which the course of our perception is set. This orbit is self-perpetuating; clothing is always 'understood through the medium of a visual convention', while the 'contemporary eye' by which the viewer receives that framing convention 'is trained by the looks of contemporary clothes.' 31 The existence of the Hollanderian dynamic is well-established. However, I want to suggest that while the naturalisation effect of a time period's style may encompass all its inhabitants, it does not necessarily affect them in the same way. That is, a decade's style will be unseeable to a different degree depending on how many previous time periods the would-be seer has experienced.

Born in a given era, we are born into its style. This may seem too obvious to need stating. However, because a period of time is absorbed as being synonymous 
with its 'look', and because both time and looking are foundational to the formation (and unavoidable deformation) of subjectivity, the fact that a period of time looks a certain way is crucial to our experience not only of it, but of ourselves. ${ }^{32}$ As is suggested by that genre of birthday card in which the year of birth is commemorated by a smattering of its most noteworthy events, a person is in some sense perceived as continuous with the cultural moment into which they are born, such that it is socially coherent to commemorate a life by reference to the era in which it began. The constitutiveness of the cultural moment, to which this practice points, is at play in the mirroring relation between one's visual sense and the style of the era, the relation on which Hollander's formation rests. When the cultural moment is that of one's birth, its particular style looks like style per se not just because it is current (the crux of the Hollanderian schema), but because one has known nothing else. The operation of the normative orbit is, in the era of birth, not yet separate from one's internal operations; its pull is more intimately ours than the same gravitational force will be in later eras. The 'look' of any decade will thus be particularly intimate for those for whom it was their first experience of style, for when we look later at the decade of our birth, the style we see, the style which stands for that decade, is that on which we first began to practise seeing. And the later return of that look, its going retro(grade), will be differently experienced, differently felt, depending on the dresser's initial age relation to the time. The style of one's era of birth will also inflect one's 'feeling' of later styles: the overall relation to time-as-style one enacts in dressing will be shaped by the style of the time in which one was first placed.

One is pressed into time by culture; not just at the moment of first entry into it, but ongoingly. As one's era of birth progresses, and with it one's cognisance of perceptual contingency, the era's defining style, while remaining naturalised, will come to be perceived in its distinctiveness. How things have always looked will give way to a new stylistic character, a new sense of what seeing means, and consequently the perception of the existence of temporalised style per se. Our decade of continuity gives rise to a decade of which our experience is of separation as much as intimacy. 33 This next decade, not the one we know as children, but the one we come into as we come out of childhood, is the age that receives our coming of age. Able to be more clearly seen as an era than the era of birth, it carries more 
visual electricity; it is the style in which we begin to see ourselves seeing. ${ }^{34}$ That period, of post-childhood into adolescence, contains both the dawning consciousness of stylistic change, and the dawning consciousness of self, stylised or not. And this brings with it a certain backwards gaze; as Richard Lawson observes, 'there's nothing an adolescent likes better than nostalgia'.35 I would argue, however, that teenage passion for nostalgia derives not, as he proposes, from a desire to feel precociously 'wizened', 36 but from the fact that adolescence is the first time one has had a past epoch for which to ache: the motion by which we first become able to perceive change is also the first experience of temporal loss.

The progress of stylistic change thus maps onto the progress of a life, individual and collective stylistic experience overlaying each other in a resist-dye pattern of emphases and refusals. Of Chanel and Schiaparelli, Vanessa Friedman writes, if a designer is successful, it's in large part because she has absorbed what's happening around her and reflected it back in sartorial form'.37 What is true from the production end is also true from the reception end (which may in another sense be that of reproduction); in our own response to fashion, we 'feel' the character of the times in the same way as a designer does, and, in the process of internalisation and externalisation by which dressing is driven, we render that feeling material. In the movement by which a temporal style's distinctiveness slips under the radar, by way of the Hollanderian dazzle effect of temporal-stylistic norms, the style camouflages with our internal experience of time per se; that is, it becomes part of us in order to not be noticed-arguably, by virtue of not being noticed. The style is the time rendered visual, and the time is part of us, and we of it, for the time it is 'now'. And so its return comes out of us: out of experience for decades we have lived through, out of imagination for decades predating us. Retro is, on this ground, an attempt to make an era visible. The retro dresser resists the disappearance of a past era's style into 'naturalness' by bringing it into an era where it, denaturalised, can be more clearly seen. Again, retro is retrograde; what I have described as the normative orbit of a style camouflaged by its contemporaneity is broken by retro's appearance of going backwards against style's forward course. However, like that of the planet in retrograde, the backwardness of retro is only apparent. In dressing under its sign, we feel through again what we had felt in (which is also to say, felt as) the past, in order to pull ourselves futurewards against that normative visual grain. 
It is not only we as individuals who 'feel' the temporal colourations of fashion, however, but the collective with whom we share the cultural present. And our present cultural moment is one pervaded by textual revenants. A Full House 'reboot' on the way; a Mallrats sequel floated; a Clueless musical in development; projected remakes of The Craft, Jumanji, Point Break and The Crow; a hologram of the late Whitney Houston set to 'tour'; the café Central Perk, social hub of Friends, recreated in New York City: the 1990s is, as they say, 'having a moment'-or our present moment is having the 1990s, and having several helpings. ${ }^{38}$ Since the 1990s has long been renowned as the decade of non-style, a determined disappearance from temporal view, perhaps its revisitations are attempts to render the time period apparent; our current conjuring of the 1990s may be aimed at finally making its spectrality visible. The period was obsessed with its own retrospectiveness, always looking back to catch itself looking back: disco-esque shimmers, sheens and sparkles; neo-Edwardian high necks, ruffles, layered lace; flower-childish daisies (imaged in prints or summoned as solid objects), gamine haircuts, dishevelment; mid-century tennis shoes or brogues or brothel-creepers. Its current comeback, consequently, is the return of all the apparitions of decades past by which it was haunted.

In this, the 1990s revival both epitomises and upsets the present's relation to the past as conceived by Roland Barthes.

As a (modern) divinity, History is repressive. History forbids us to be out of time. Of the past we tolerate only the ruin, the monument, kitsch, what is amusing; we reduce this past to no more than its signature. 39 The current incarnation of the 1990s (amounting, perhaps, to a monumentalisation of kitsch) is the return of a ruin which was itself the picked rags of other eras. It is something like a real signature on a copied painting; a doubled pretence, and just the sort of verificatory anachronism beloved of those stylistic bowerbirds we know as hipsters, of whom Daniel Renfrow writes that they realise their appetite for irony in combinations like 'a bowler hat worn with a pair of thick rimmed glasses from the '50s and a Metallica shirt under a cardigan...'40 So perhaps what makes Cher's closet an icon for the 1990s is its function of combining: the decade created, and the closet makes visual, a stylistic buffet at which our own era continues merrily to eat. Barthes asserts that one of the functions of 'the rhetoric of Fashion ... is to blur the 
memory of past Fashions'. To achieve this, it 'discredits the terms of past Fashion, making those of current Fashion euphoric'. ${ }^{41}$ In our current era's fetish for being everywhere at once, the fashions of the past are blurred not by being improperly remembered, but by being pluralised and ironically recombined. The mania of our present's fashion consists of every past and many a possible future thrown in an ofthe-moment blender (a Thermomix, perhaps?), amounting less to euphoria than to something like temporal motion sickness.

To return to the equally puréed plurality of Friends, that canonical text of 1990s revivalism: stylistically speaking, when members of my generation-teenagers in the 1990s-look now at the sitcom, we are looking at characters who are nominally, as represented then, the age we are now. The show was the image, for us, in adolescence, of how adulthood was imagined to look; with the contemporary return of 1990s style, the epoch of our adulthood looks very much as imag(in)ed. Christene Barberich says, of her own investment in clothes from previous life-phases, that people who 'share a real kinship with clothes' are those who 'like how much [clothes] can tell the story of who you are'.42 In the case of Friends' uncanny collapse of present with a past future, my generation is experiencing the story we were told of what we would be (which, having been seen once before, is also the 'story of what was') telling the further story of what is, the style of our narrative 'now'.43 We thus have the uncanny experience of converging, on the level of style, with our own anticipations, as though the text were a strange shaken-up kind of premonition, a Magic 8-Ball of memory and vision; as though we are ourselves replaying, on the level of visual-sartorial experience, the temporal repetition that characterises another irreducibly 1990s text, Groundhog Day.44 What was the future, and adulthood, is now the past, but having a stylistic return: a second adolescence.

It could be argued that the current return of the 1990s rests precisely on this perpetual adolescence; that it is matched, in the way of garments in Cher's automated closet, with a cultural investment in the infinite deferral of adulthood. As Frances McDormand observes, in the present: 'Adulthood is not a goal. Something happened culturally. No one is supposed to age past 45-sartorially, cosmetically, attitudinally. Everybody dresses like a teenager ... Everybody is concerned about a smooth face.'45 Our adolescence, as the teenagers of the 1990s, never went awayand now, having returned with the force of an imperative, it is everyone's 
adolescence. 'Everybody dresses like a teenager'-and in the style of the 1990s, which was itself pervaded by an atmospheric adolescence. 'I don't care if forever never comes/ Cos I'm holding out for that teenage feeling', sings Neko Case, in what could be nostalgia's rational anthem. ${ }^{46}$ In the view of Amy, my resident 1990s aficionado, 'the '90s was everyone-even the adults-dressing like teenagers trying to look grown-up'.47 The decade's overarching style was adolescent, even if one's own temporal location within it was adult. (Revealingly, Clueless had a working title of I Was a Teenage Teenager, distinguishing, or perhaps doubling, the lived adolescence of its characters and the styled adolescence of the decade in general. ${ }^{48}$ )

It is as though what was stylistic contingency in the 1990s-the appearance of adolescence-became, through some changing of the cultural wind, aesthetic necessity. It was a face we pulled, and now it is our cultural face. It is, however, a face we hide. For, as Amy observes, the essence of 1990s style was 'trying so hard not to try'. ${ }^{49}$ This captures an important aspect of the decade's aesthetic avoidance of itself (or of its own existence as an aesthetic); it is not that we, in the 1990s, were trying and then covering it up, but trying not to try at all. This is harder than it looks, especially when you're trying to make it look easy, and an apt manifesto for what used to be called the 'slacker' generation. Effort expended in the avoidance of the appearance of effort is central to adolescence, and thus the intrinsically teenage 'feeling' of the 1990s and its quality of trying to not try are sides of the same coin. Further, effort which must erase itself has the force of an imperative where femininity is concerned, and so Amy's formulation of 'trying not to try' goes doubly for teenage girls; once for their position under gendered pressure, twice for their adolescence. 50 To enter another textual hall of temporal mirrors, the position of the 1990s teenager is that enacted in the opening scene of Grease, a film paradigmatically both adolescent and nostalgic. As the swaggeringly feminine Pink Ladies arrive at school, the least poised member, Jan, is told by the more sophisticated Marty that her messy eating of an Oreo cookie is 'so adolescent'. Jan responds laughingly, 'We are adolescents!' The lead Lady, Rizzo, interjects: 'Yeah, but we don't have to flaunt it.'51 Far from flaunting, the 1990s adolescent expended a tandem effort of investment and concealment in order, remaining with Grease's image, to have our cookie and not eat it, too. And so the stylistic return of that 
adolescence brings with it both the effort required to remain forever young, and its disavowal.

The looking-back within these texts, and our seemingly bottomless cultural appetite for looking back at them, produces a temporal circularity central to the corporeal internalisation of retro dress. Carrying eras with us, in all their tangled specificity of alignment with our own temporal course, we are formed by their return, in us and in the broader culture; carrying ourselves through time by means of the styles of our various pasts, and their felt effect on our aesthetic comportment, we return to them to get a bearing on how time moves us. The present is, in Arendt's view, 'in ordinary life the most futile and slippery of the tenses', for 'when I say "now" and point to it, it is already gone'.52 The evanescence of the 'now' drives its inhabitants-us-to memoralise other time periods, to which we can more readily 'point'. (It might also explain the lure of dressing towards adolescence, that state of perpetual 'now'.) The fashion-oriented application of 'feeling' is present tense, and continuous, as is the condensed complexity of the moment of dressing. And yet, even in that present, we are losing the moment as we name it; hence the need to make, corporeally-sartorially, a 'now' of various 'thens' and 'hences' to stitch us crosswards into time. As, in Arendt's formulation, we withdraw ourselves, in thinking, from the interpersonal world in order to conceive of it, so do we withdraw, in dressing, from the visual-material world in order to conceive ourselves in it anew. Having taken in cultural time, textually and sensorily, we remake it by means of our own image. 'We find our place in time when we think',53 and when we dress, we are corporeally thinking through our own experience of 'when' - the already-been, the elusive 'now', the yet-to-be-as visual feeling.

Stella North is an independent scholar of gender and cultural studies, a discipline in which she holds a PhD from the University of Sydney. Her overarching interest in fashion and embodiment has led to her current interest in visual-cultural manifestations of nostalgia, a focus she combines with other research interests, including twentieth-century literature, feminist theory and psychoanalysis. 
-Notes

${ }_{1}$ Against the plurality of dressed experience, there is the singularity of subject position, with all its inflections and constraints; the 'we' I here speak of, and from, is that of white women in the contemporary West, though I am by no means suggesting that this position can account for all potential relations to dress.

2 Hannah Arendt, 'Book One: Thinking', in The Life of the Mind, Harcourt, San Diego, 1978, p. 199. As I

will come to explain, this dealing in absences which Arendt finds characteristic of thought is not a straightforward evacuation of perception, but a way of making present, in absence, things which otherwise fall beneath the surface of ordinary perception. This is to say, in her vision of 'thinking' as in the vision of dressing to which I here apply it, absence and presence are never cleanly differentiated, but rather feed back into one another.

${ }^{3}$ Arendt, p. 203.

${ }^{4}$ Karen Tranberg Hansen, 'Crafting Appearances: The Second Hand Clothing Trade in Zambia', in Alexandra Palmer and Hazel Clark (eds), Old Clothes, New Looks: Second Hand Fashion, Berg, Oxford, 2005, p. 104.

${ }^{5}$ For example, in Piper Weiss's My Mom, Style Icon, Bea Whitney says of her mother 'I love how she always looked so simply put-together' (p. 125), while John Buffalo Mailer says of his mother that he 'can't pretend to be as well put together' as she was (p. 88); Piper Weiss, My Mom, Style Icon, Chronicle, San Francisco, 2011.

${ }^{6}$ I have expatiated upon this conception of clothing as fundamentally corporealised, and corporeality as correspondingly thoroughly sartorialised, in 'Clothing the Space of Flesh: Fashion as Material Narration', PhD thesis, University of Sydney, 2014.

${ }^{7}$ Clueless, dir. Amy Heckerling, 1995.

${ }^{8}$ Lorelei Vashti, Dress, Memory: A Memoir of my Twenties in Dresses, Allen \& Unwin, Sydney, 2014, p. 68.

9 Examples, from Imogen Edwards-Jones's mock memoir Fashion Babylon: 'what are we feeling for Fall?' (p. 74); 'I'm feeling that waists are back' (p. 107); 'I think we are all feeling black and silver and a bit geometric' (p. 122); 'I'm feeling that outfit' (p. 250); 'I'm feeling nude eyes' (p. 332), to name but a few; Imogen Edwards-Jones, Fashion Babylon, Random House, London, 2011.

${ }^{10}$ Leanne Shapton, 'Covet Diary: Regarding the Dress of Another', in Sheila Heti, Heidi Julavits and Leanne Shapton (eds), Women in Clothes, Blue Rider Press, New York, 2014, p. 435.

11 I owe the conception of the Plimsoll Line as a figure of perception to Linda Bayer.

12 Arendt, p. 85.

13 For my more detailed discussion of the significance of clothing as a corporeal surface, and its importance, as that surface, to psychic experience, see 'The Surfacing of the Self: The Clothing-Ego' in Sheila Cavanagh, Angela Failler and Rachel Alpha Johnston Hurst (eds), Skin, Culture and Psychoanalysis, Hampshire, Palgrave, 2013, pp. 64-89. 
14 Arendt, p. 206.

15 Ibid., p. 210.

16 Ibid., p. 205. The quoted phrase 'the quiet of the past' goes unreferenced in Arendt's text; my guess is that it is an allusion to Abraham Lincoln's reference, in his 1862 Annual Message to Congress, to 'the dogmas of the quiet past'.

17 Dar Williams, 'It's Alright', from the album Promised Land, Razor and Tie Records, 2008.

${ }^{18}$ Arendt develops this argument progessively over the course of The Life of the Mind, but see, in particular, the chapter on 'Invisibility and Withdrawal', in which she describes how, because 'plurality is one of the basic existential conditions of human life on earth', such that 'inter homines esse, to be among men [sic], was to the Romans the sign of being alive, aware of the realness of world and self', the ability 'to be by myself and to have intercourse with myself is the outstanding characteristic of the life of the mind' (p. 74). This inward intercourse, what she calls 'the soundless dialogue of the I with itself' (pp. 74-5), a 'sheer self-awareness of which I am, as it were, unconsciously conscious' (p. 75), recedes into the background with my re-entrance into the social world, when the 'thinking ego, of which I am perfectly conscious so long as the thinking experience lasts, will disappear as though it were a mere mirage' (p. 75).

${ }^{19}$ Arendt, p. 210.

20 The common assumption is that 'vintage fashion is clothing that is at least 25 years old' (p. 6) and that 'retro' marks 'Sixties and Seventies casual wear' (p. 112), Funmi Odulate, Shopping for Vintage: The Definitive Guide to Vintage Fashion, Quadrille, London, 2007.

${ }^{21}$ Richard Lawson attributes both the narrowing of retro's span and the speeding-up of stylistic change to the increased capabilities of the internet, 'a veritable nostalgia machine'. The 1990s' potential for nostalgic revisitation, he argues, was 'used up so much faster' than that of the 1980s, 'likely because the internet got faster'. Consequently, the decade's pop-cultural artefacts 'were picked over like a timelapse animal carcass covered in ants', ushering in nostalgia for the 2000s even sooner than could have been expected, 'Too Soon? Welcome to '00s Nostalgia', The Wire, 29 March 2012, <http://www.thewire.com/entertainment/2012/03/anchorman-2-and-rise-00s-nostalgia/50525/>. 22 The entry for 'retro' in The Encylopaedia of Fashion has it 'used in France in the second half of the 20th century to describe clothes from another era, usually pre-World War II, which are enjoying a revival' (p. 213). (It can be assumed that the pre-war demarcation is being measured from the 1950s and 1960s, as the distance between them is that traditional two to three decade span of retro.) Georgina O'Hara, The Encylopaedia of Fashion, Thames and Hudson, London, 1986.

23 This phrase, 'the past made cloth', rests on an earlier coinage of 'the word made cloth'; for the explication of this concept, see my 'Clothing the Space of Flesh'.

${ }^{24}$ Retro as 'fashion term' was coined in the 1960s, from French rétro, an abbreviation of rétrograde, 'retrograde', <http://oxforddictionaries.com/definition/english/retro>. 
25 Hilary Alexander quoted in Odulate, p. 119. While she is speaking of 'vintage' rather than 'retro', in the case I am making for retro as an approach, the two are one in their effect.

26 The 'time travel' metaphor is one commonly used in fashion press descriptions of retro. See, for example, blogger and designer Jacqueline Stewart's post '90s Time Travel: Alternative Curves', Fashion and Pho, 15 December 2014, <http://www.fashionpho.com/2014/12/15/90s-time-travel-alternativecurves/>.

${ }^{27}$ Friends, created by Marta Kauffman and David Crane, NBC, 1994-2004. The particular Season One ensembles I am thinking of are: a high-necked top worn under a embroidered jacket with a long, full skirt (Episode 15: 'The One With the Stoned Guy'), and a later high-waisted floral skirt worn with a matching painted waistcoat (Episode 24: 'The One Where Rachel Finds Out').

28 Fashion journalist Laura Weir sees the prevalence of 1970s looks on the Resort 2014 and Spring/Summer 2015 catwalks as 'proof that retro has reached its apex'. 'Return to Retro', Vogue, 23 December 2014 <http://www.vogue.co.uk/fashion/trends/2015-spring-summer/return-to-retro>. ${ }^{29}$ Alexander Nagel, interviewed by Sheila Heti, 'The Surfer is Nothing Without the Wave', in Heti, Julavits and Shapton, p. 187.

${ }^{30}$ Anne Hollander, Seeing Through Clothes, University of California Press, Berkeley, 1993, p. xiii. Hollander's argument unfolds through an examination of art history; the representation by which an era's style is alchemically naturalised is that of visual art, primarily painting. In a given era, she explains, 'while the ordinary body was dressed, it would feel itself to appear in harmony with the contemporary style of art in which nature was made to look real. This correspondence is what would produce a sense of natural looks' (p. xii).

31 Ibid., pp. xiii, 86.

32 This line of argument rests on the perspective of psychoanalysis, in which the infantile acquisition of the ability to distinguish oneself from the material world is of fundamental developmental, and consequently lasting psychical, importance. While it is beyond my scope here to map the potential contribution of style to this formation of subjectivity through differentiation, I have touched on it in 'The Surfacing of the Self', and I imagine it to be fruitful terrain for further enquiry.

33 It seems likely that the realisation of stylistic transience might transpire around the age of ten, that is, the point at which one has seen the passage of a decade-of time, if not a discrete swathe of style. I am grateful to Helane Nimerawi for bringing this implication to my attention.

34 Katie Hoffman makes this point in regard to the 2000s, her era of adolescence. That decade was when she and her peers 'first started thinking about how our appearances could be an extension of our identities', and as a result she feels the incipient return of the era's style to be 'the reopening [of] a time capsule' of her past. She suggests that her generation's view of that return, albeit 'biased by nostalgia' should be one in which 'the clothes we wore and the way we styled our hair' are thought of 'as a rite of passage'. '17 Nostalgic Fashion Trends From The Early 2000s That Will Make You Miss Your Tattoo 
Choker', Bustle, 18 March 2015 <http://www.bustle.com/articles/69892-17-nostalgic-fashion-trendsfrom-the-early-2000s-that-will-make-you-miss-your-tattoo-choker>.

35 Lawson.

36 Ibid.

37 Vanessa Friedman, 'In Their Fashion: New Books About Coco Chanel and Elsa Schiaparelli', New York Times, 3 October 2014, <http://www.nytimes.com/2014/10/05/books/review/new-books-aboutcoco-chanel-and-elsa-schiaparelli.html>.

38 Original dates of films and television series mentioned:

Full House, 1987-1995.

Mallrats, 1995.

Clueless, 1995.

The Craft, 1996.

Jumanji, 1995.

Point Break, 1991.

The Crow, 1994.

Friends, 1994-2004.

${ }^{39}$ Roland Barthes, A Lover's Discourse: Fragments (Fragments d'un discourse amoureux, 1977), trans. Richard Howard, Vintage, London, 2002, p. 177.

40 Daniel Renfrow, 'Survival Guide: How to Identify, Avoid Hipsters', The Daily Cougar, 25 February 2011, <http://thedailycougar.com/2011/02/25/survival-guide-identify-avoid-hipsters/>.

41 Roland Barthes, 'Appendix' to The Fashion System (Systeme de la Mode, 1967), trans. Matthew Ward and Richard Howard, University of California Press, Berkeley, 1990, p. 300.

42 Christene Barberich, 'Stacy London “What Not To Wear-ed” My Closet', Refinery29, 11 July 2015, $<$ http://www.refinery29.com/closet-organizational-tips>.

43 Ani DiFranco, 'The True Story of What Was', from the album Educated Guess, Righteous Babe Records, 2004.

44 Groundhog Day, dir. Harold Ramis, 1993. As irony would have it, this is another 1990s text being remade: a musical version premieres in London in 2016.

45 Frances McDormand, quoted in Frank Bruni, 'A Star Who Has No Time for Vanity: Frances

McDormand, True to Herself in HBO's Olive Kitteridge', New York Times, 14 October 2015,

$<$ http://www.nytimes.com/2014/10/19/arts/frances-mc-dormand-true-to-herself-in-hbos-olivekitteridge.html>.

46 Neko Case, 'That Teenage Feeling', from the album Fox Confessor Brings the Flood, Shock Records, 2006.

47 Amy McGregor, personal communication, 17 February 2015.

48 Jen Chaney, 'The Definitive Oral History of How Clueless Became an Iconic 90s Classic', Vanity Fair, July 2015, <http://www.vanityfair.com/hollywood/2015/06/clueless-oral-history-20-anniversary>. 
49 McGregor; emphasis in original. I am indebted to Amy for many productive analyses of the 1990s, as experienced then and now.

50 To name only one of the most widely cited examples of research in this area: in a Duke University study of women's gendered experience in higher education, a female student described how women operate under an expectation of 'effortless perfection' (p. 12). The phrase then gained currency in contemporary feminist discussions of the pressures of normative femininity. Susan Roth, Women's Initiative, intro. Nannerl O. Keohane, Duke Publications Group, Durham, 2003.

51 Grease, dir. Randal Kleiser, 1978.

52 Arendt, p. 205.

53 Ibid., p. 209.

\section{-BiBLIOGRAPHY}

Arendt, H., The Life of the Mind, Harcourt, San Diego, 1978.

Barberich, C., 'Stacy London “What Not To Wear-ed” My Closet', Refinery29, 11 July 2015, $<$ http://www.refinery29.com/closet-organizational-tips>.

Barthes, R., A Lover's Discourse: Fragments, trans. Richard Howard, Vintage, London, 2002.

Barthes, R., The Fashion System, trans. Matthew Ward and Richard Howard, University of California Press, Berkeley, 1990.

Bruni, F., 'A Star Who Has No Time for Vanity: Frances McDormand, True to Herself in HBO's Olive Kitteridge', New York Times, 14 October 2015, <http://www.nytimes.com/2014/10/19/arts/frances-mc-dormand-true-to-herself-in-hbosolive-kitteridge.html>.

Cavanagh, S., A. Failler and R. A. Johnston Hurst (eds), Skin, Culture and Psychoanalysis, Hampshire, Palgrave, 2013. doi: http://dx.doi.org/10.1057/9781137300041

Chaney, J., 'The Definitive Oral History of How Clueless Became an Iconic 90s Classic', Vanity Fair, July 2015, <http://www.vanityfair.com/hollywood/2015/06/clueless-oral-history-20anniversary>.

Edwards-Jones, I., Fashion Babylon, Random House, London, 2011.

Friedman, V., 'In Their Fashion: New Books About Coco Chanel and Elsa Schiaparelli', New York Times, 3 October 2014, <http://www.nytimes.com/2014/10/05/books/review/new-books-about-cocochanel-and-elsa-schiaparelli.html>.

Hansen, K.T., 'Crafting Appearances: The Second Hand Clothing Trade in Zambia', in A, Palmer and H. Clark (eds), Old Clothes, New Looks: Second Hand Fashion, Berg, Oxford, 2005.

Heti, S., H. Julavits and L. Shapton (eds), Women in Clothes, Blue Rider Press, New York, 2014.

Hoffman, K. '17 Nostalgic Fashion Trends From The Early 2000s That Will Make You Miss Your Tattoo Choker', Bustle, 18 March 2015, <http://www.bustle.com/articles/69892-17-nostalgic-fashiontrends-from-the-early-2000s-that-will-make-you-miss-your-tattoo-choker>. 
Hollander, A., Seeing Through Clothes, University of California Press, Berkeley, 1993.

Lawson, R., 'Too Soon? Welcome to '00s Nostalgia', The Wire, 29 March 2012,

<http://www.thewire.com/entertainment/2012/03/anchorman/-2-and-rise-00s-

nostalgia/50525/>.

North, S., 'Clothing the Space of Flesh: Fashion as Material Narration', PhD thesis, University of Sydney, 2014.

North, S., 'The Surfacing of the Self: The Clothing-Ego', in S. Cavanagh, A. Failler and R.A. Johnston Hurst (eds), Skin, Culture and Psychoanalysis, Hampshire, Palgrave, 2013. doi:

http://dx.doi.org/10.1057/9781137300041.0008

O’Hara, G., The Encylopaedia of Fashion, Thames and Hudson, London, 1986.

Odulate, F., Shopping for Vintage: The Definitive Guide to Vintage Fashion, Quadrille, London, 2007.

Renfrow, D., 'Survival Guide: How to Identify, Avoid Hipsters', The Daily Cougar, 25 February 2011, <http://thedailycougar.com/2011/02/25/survival-guide-identify-avoid-hipsters/>.

Roth, S., Women's Initiative, intro. N.O. Keohane, Duke Publications Group, Durham, 2003.

Shapton, L., 'Covet Diary: Regarding the Dress of Another', in S. Heti, H. Julavits and L. Shapton (eds), Women in Clothes, Blue Rider Press, New York, 2014.

Stewart, J., '90s Time Travel: Alternative Curves', Fashion and Pho, 15 December 2014, <http://www.fashionpho.com/2014/12/15/90s-time-travel-alternative-curves/>.

Vashti, L., Dress, Memory: A Memoir of my Twenties in Dresses, Allen \& Unwin, Sydney, 2014.

Weir, L., 'Return to Retro,' Vogue, 23 December 2014, <http://www.vogue.co.uk/fashion/trends/2015spring-summer/return-to-retro>.

Weiss, P., My Mom, Style Icon, Chronicle, San Francisco, 2011. 